\title{
Determining compliance in clean intermittent catheterization for children with sensate urethra
}

\author{
Walid A. Farhat, MD, FRCSC, FAAP
}

See related article on page 403.

Can Urol Assoc J 2010;4(6):406.

$\mathrm{t}$ is known that clean intermittent catheterization is more difficult for children and their parents; the normal genital sensation may cause pain and distress during catheterization attempts and afterwards. Neel presents evidence that clean intermittent catheterization is feasible in children with a sensate urethra. ${ }^{1}$ The quality of life in the children with a sensate urethra has been previously investigated in the literature, and was found to be comparable to those children without a sensate urethra. ${ }^{2}$

Neel highlights the feasibility of doing clean intermittent catheterization for those patients, but we are still lacking information on whether the frequencies of the catheterization, in addition to the age of the children, have any impact on compliance.

Most of the time, the frequency of catheterization depends on the primary pathology. For instance, posterior urethral valve and non-neuropathic bladder sphincter dysfunction patients may be managed with double voiding. In these cases, catheterization can sometimes be used as an adjunct to double voiding, and some children may do well with double voiding and would not need catheterization; therefore, compliance may not accurately be determined.

As for age, the authors reported that children under the age of 4 years are more compliant. This illustrates that the earlier catheterization is introduced to children, the better they are at being compliant with it. Finally, when we talk about compliance, outcome should be a variable measure; it is mandatory to correlate the frequency of the catheterization, the size of the catheter and the age of the patient to the final outcome (i.e., upper tract changes, urinary tract infections or incontinence episodes).

Pediatric Urologist, SickKids, Associate Professor, University of Toronto, Toronto, ON

Competing interests: None declared.

This paper has been peer-reviewed.

\section{References}

1. Neel KF. Feasibility and outcome of clean intermittent catheterization for children with sensate urethra. Can Urol Assoc J 2010;4:403-5.

2. Alpert SA, Cheng EY, Zebold KF, et al. Clean intermittent catheterization in genitally sensate children: patient experience with health related quality of life. J Urol 2005;174:1616-9.

Correspondence: Dr. Walid A. Farhat, The Hospital for Sick Children, 555 University Ave., Toronto, ON M5G 1X8; fax: 416-813-6461; walid.farhat@sickkids.ca 